\title{
Perfil e desenvolvimento neuropsicomotor de crianças beneficiárias e não beneficiárias do Programa Bolsa Família
}

\author{
Larissa Araujo Matos* \\ Edson Júnior Silva da cruz** \\ Lilia Iêda Chaves Cavalcante***
}

\begin{abstract}
Resumo
O objetivo deste estudo foi descrever o perfil e o desenvolvimento neuropsicomotor de 319 crianças beneficiárias e não beneficiárias do Programa Bolsa Família, que frequentavam Unidades de Educação Infantil localizadas em Belém-PA. Os instrumentos utilizados foram questionário para caracterização biopsicossocial da criança, um instrumento de medição do nível de pobreza da família e o Teste de Triagem do Desenvolvimento Denver II. O perfil do desenvolvimento neuropsicomotor das crianças beneficiárias e não-beneficiárias que foram avaliadas não apresentou diferença significativa, contudo a análise estatística dos dados sugere a existência de correlação significativa entre o nível de pobreza e o perfil do desenvolvimento neuropsicomotor dos dois grupos $\mathrm{p}=0003$. O estudo apontou a relação entre os fatores ambientais e o perfil suspeito do desenvolvimento neuropsicomotor das crianças avaliadas, em particular devido a condição de pobreza das famílias. Mesmo o grupo que tinha acesso ao beneficio social do Programa bolsa família este não alterou a condição de pobreza e riscos para o desenvolvimento neuropsicomotor.

Palavras-chave: Desenvolvimento neuropsicomotor; família; educação infantil; pobreza
\end{abstract}

\begin{abstract}
The objective of this study was to describe the profile and neuropsychomotor development of 319 beneficiary and non-beneficiary children of the Bolsa Família Program that attended Educational Units Children located in Belém-PA. The instruments used were a questionnaire for biopsychosocial characterization of the child, a family poverty level measurement instrument, and the Denver II Development Screening Test. The neuropsychomotor development profile of the beneficiary and non-beneficiary children that were evaluated did not present a significant difference, however, the statistical analysis of the data suggests a significant correlation between the poverty level and the neuropsychomotor development profile of the two groups $\mathrm{p}=0003$. The study points out the relationship between the neuropsychomotor development of the children evaluated and environmental factors as the poverty condition of the families, although one group has access to direct social benefits, this does not change the poverty condition and risks to neuropsychomotor development.
\end{abstract}

Key-words: Neuropsychomotor development; family; child education; poverty

* Assistente Social. Mestre em Teoria do Comportamento pela UFPA. Professora do Curso de Serviço Social da UNIP.

** Assistente Social. Mestre em Psicologia Social e Doutorando do Programa de Psicologia da UFPA.

***Professora da Faculdade de Serviço Social da Universidade Federal do Pará e orientadora no Programa de Pós-Graduação em Teoria e Pesquisa do Comportamento. Mestre em Serviço Social e Doutora pelo Programa de Pós-Graduação em Teoria e Pesquisa do Comportamento da Universidade Federal do Pará. Pós-Doutorado pelo Programa de Pós-Graduação em Psicologia da Universidade Federal do Rio Grande do Sul. 


\section{Introdução}

Ao estudar o desenvolvimento neuropsicomotor é importante considerar os aspectos sociais, como o nível socioeconômico, vulnerabilidade de indivíduos, famílias e populações, visto que estes exercem significativa influência nos estágios iniciais do desenvolvimento humano, especialmente em países como o Brasil. Vale ressaltar que o desenvolvimento neuropsicomotor ocorre por meio de mudanças complexas que envolvem uma etapa de maturação, aprendizagem e fatores psicossociais que é caracterizada por domínios funcionais que envolve cognição, linguagem, coordenação motora fina e ampla, funções sensoriais e amadurecimento socioemocional que estão interligados a maturação neural e influência do ambiente (Cole \& Cole, 2008; Eickmann, Malkes \& Lima, 2012).

Os altos índices de desigualdade social propiciam a exposição de crianças a condições de risco, acesso inadequado a serviços básicos, escassez de alimento, violência e danos à saúde física e mental. E os níveis de pobreza influenciam o curso considerado saudável deste estágio do desenvolvimento (Rizzini, 2009; Delvan, Becker \& Braun, 2010).

Neste estudo, a discussão sobre pobreza ganha destaque uma vez que se compreende este fenômeno como uma realidade de privação multidimensional na qual o ser humano pode estar situado em uma posição de cerceamento que compromete a realização de suas necessidades básicas, como alimentação, segurança, educação, lazer e saúde. Além disso, o indivíduo pode estar envolto em correntes ideológicas de marginalização e de culpabilização pela sua situação. Desse modo, a pobreza tem sido vista como um estado no qual o ser humano está inserido em condições adversas de sobrevivência material e simbólica (Cidade, Moura Junior \& Ximenes, 2012).

A pobreza é um fator considerável que pode alterar a trajetória do desenvolvimento cognitivo, socioemocional e ocasionar ou intensificar problemas desenvolvimentais durante todo o ciclo de vida. Em condição de pobreza, algumas crianças são expostas a poucos estímulos; utilizam brinquedos inadequados para a idade; têm menos lugares fora da escola para aprender e estabelecer vínculos e geralmente vivem em ambientes onde se lê e fala pouco. Em razão disso, estudos mostram que crianças que vivem em ambiente com pouca estimulação à linguagem apresentam um vocabulário limitado o que consequentemente reflete em outras questões como: dificuldade para aprender ler e escrever, pouca interação social e atraso escolar (Delvan, Becker \& Braun, 2010; Evans \& Kim, 2013).

No âmbito dessa discussão, a pobreza tem sido considerada como um tipo de ameaça constante que aumenta a vulnerabilidade da criança, pois pode causar subnutrição, privação social e desvantagem educacional. Crescer na pobreza consiste em uma ameaça ao bem-estar da criança e uma limitação colocada às oportunidades de desenvolvimento, principalmente quando essa criança e sua família não possuem uma rede de apoio social adequada e de qualidade. Também quando não recebem ou participam de algum programa que possa melhorar ou amenizar sua condição socioeconômica (Cidade, Junior \& Ximenes, 2012; Engel de Abreu, Tourinho, Puglisi, Nikaedo, Abreu, Miranda, Befi-Lopes, Bueno \& Martin, 2015).

A condição socioeconômica desfavorável das famílias é um fator que não vem desacompanhado, pois permeia a relação conjugal, o que contribui para o aumento da incidência de conflitos entre os pais e produz um efeito direto no relacionamento destes com a criança (Pilz \& Scherman, 2007, Moura Jr, Cidade, Ximenes \& Sarriera, 2014). Consequentemente, uma renda insatisfatória influencia na qualidade das moradias. Ao analisar a condição de superfície em que se encontram os domicílios precários do município de Belém observou-se que, as construções mais comuns em terrenos alagáveis são as de madeira pertencentes a famílias das camadas sociais mais baixas (Sá, Lopes, Cruz, Costa \& Cardoso, 2009).

Em razão dos efeitos nefastos da exposição à pobreza para o desenvolvimento humano, é imperiosa a compreensão acerca das políticas sociais como resposta às demandas colocadas por essa condição adversa, sobretudo nos anos iniciais da infância. Esta situação é vivenciada nos países (Brasil, Haiti, Bolívia, Venezuela) que possuem pessoas/famílias que vivem em condição de pobreza absoluta, fenômeno associado à grande concentração de renda e diferentes processos de desigualdade social. A presença da pobreza, cada vez maior, em vastas áreas do mundo decorre de um rearranjo do mercado capitalista que produz um contingente expressivo de trabalhadores, que tem seu trabalho precarizado ou vivenciam o desemprego estrutural, demandando do Estado ações de proteção social (Silva, Yazbek \& Giovanni, 2011).

A pobreza vai além da ausência de recursos materiais, de modo que ela é expressão direta das relações sociais estabelecidas (Ammann, 2013). Sendo assim, o modo como a sociedade se organiza produz e reproduz a desigualdade social, fazendo com que as pessoas que se encontram em situação de pobreza sejam vistas de maneira negativa por suas crenças, por sua classe social e seus valores culturais. Diante deste cenário, são criados 
mecanismos pelo Estado para tentar amenizar a situação de pobreza de milhares de famílias, estes mecanismos são também as políticas sociais, como por exemplo a política de assistência social, que tem o objetivo de promover o mínimo básico para que o indivíduo inicie um processo de promoção humana e de reprodução da força de trabalho. (Behring, 2003).

Dentre as políticas sociais que se propõem a enfrentar as formas mais extremas de pobreza, cabe mencionar os Programas de Transferência de Renda, que, no Brasil, começaram a fazer parte da agenda pública a partir da década de 1990 e integram o Sistema Brasileiro de Proteção Social (Silva, 2007). Dentre esses programas, destaca-se o Programa Bolsa Família (PBF), que é o maior e mais importante programa social do Brasil e também um dos maiores do mundo, representando o eixo principal da proteção social nas situações em que a pobreza deixa milhares de famílias em situação de vulnerabilidade (Silva, Yazbek \& Giovanni, 2011).

O Programa Bolsa Família foi criado pela Medida Provisória n. 132, de 20 de outubro de 2003, transformada na Lei n. 10.836, de 9 de janeiro de 2004 e regulamentada pelo Decreto n. 5.209, de 17 de setembro de 2004. Constitui uma política intersetorial que unificou programas dessa natureza (Bolsa Escola, Bolsa Alimentação, Cartão Alimentação e Vale Gás). Ele integra o Plano Brasil Sem Miséria (BSM), que tem como objetivo elevar a renda e as condições de bem-estar de famílias extremamente pobres e se pauta na garantia de renda, inclusão produtiva e no acesso aos serviços públicos (Brasil, 2015). Constitui-se também uma das principais estratégias do Programa Fome Zero, sendo que a sua principal meta é representada pelo conjunto de políticas governamentais e não governamentais cujo propósito maior é erradicar a fome e a desnutrição no país (Brasil, 2015).

O Ministério do Desenvolvimento Social e Combate à Fome (Brasil, 2015) apresenta três principais eixos de atuação do PBF: a) transferência de renda que promove o alívio imediato da pobreza; b) condicionalidades que reforçam o acesso a direitos sociais básicos nas áreas de educação, saúde e assistência social; c) ações e programas complementares que objetivam o desenvolvimento das famílias, de modo que os beneficiários consigam superar a situação de vulnerabilidade.

Para receber o benefício, as famílias devem estar inscritas no Cadastro Único para Programas Sociais do Governo Federal (CadÚnico). A seleção dos beneficiários do PBF é conduzida nos municípios com base nas informações do CadÚnico que tem como objetivo iden- tificar e caracterizar as famílias de baixa renda no Brasil (Brasil, 2015).

À medida que o programa se propõe a combater a pobreza das famílias beneficiadas, pode ser considerado como um fator de proteção a esses sujeitos, pois estudos sugerem que o programa teve impactos positivos em vários aspectos da vida das famílias beneficiárias (Silva, 2007). Em relação à educação, por exemplo, houve o aumento da frequência e diminuição na evasão escolar entre as crianças beneficiadas (Soares, Ribas \& Osório, 2010).

Outro efeito positivo do programa diz respeito à renda. O estudo de Soares, Ribas e Osório (2010), mostrou que, neste aspecto, a política pública de combate à pobreza está sendo eficiente, pois além de bem focalizada, também aumentou a renda e o consumo dos estratos mais pobres da sociedade brasileira. Dentre as famílias que não apresentam renda fixa além do PBF, o dinheiro serve para garantir o sustento e impedir que a família vivencie situações de fome, já para as famílias em que o PBF é uma renda complementar o dinheiro é investido na compra mais diversificada de alimentos e outros utensílios como roupas, material escolar, entre outros.

Apesar dos limites do programa, o esforço da unificação de programas sociais, em si, representa um avanço para a política social brasileira, marcada historicamente por grande diversidade de programas fragmentados, desarticulados e insuficientes. A autora ressalta a dimensão do PBF e o caráter intersetorial do programa, a abrangência geográfica e quantitativa das famílias atendidas. Aponta, ainda, que o foco na família e o incremento de investimento destinado ao programa em 2010 alcançou a média de um bilhão de reais mensais, o que permite considerar que este é o maior programa social já desenvolvido no âmbito da proteção social no Brasil. Entretanto, considera-se que isso não significa que a superação da pobreza no país esteja próxima, mas sim que há um esforço significativo de administração e de controle de modo a contribuir para que a pobreza mantida num determinado patamar não avance (Silva, 2007).

Contudo, mesmo diante de estudos que sugerem melhorias nos indicadores socioeconômicos de parcelas expressivas da população brasileira beneficiadas pelo PBF, há de se problematizar as condições imediatas na vida das famílias beneficiadas (acesso a bens e serviços socialmente produzidos e que são promotores do desenvolvimento), em todos os seus aspectos, e não apenas como um meio de manter controle social dos pobres (Rosinke, Heck, Dalfovo \& Ruscheinsky, 2016; Soares, Ribas e Osório, 2010). 
Estudos recentes (Soares, Ribas e Osório, 2010; Cidade, Moura Junior \& Ximenes, 2012) na literatura de diferentes áreas, como o serviço social e a psicologia, começam a discutir essa questão. Questiona-se, especialmente, se o PBF pode ser reconhecido como um programa social capaz de promover mudanças abrangentes na condição de vida de famílias que são suas beneficiárias. Pois, o PBF é destinado prioritariamente aos segmentos em vulnerabilidade social e se apresenta como capaz de erradicar a pobreza na sua face mais cruel e, com isso, promover o desenvolvimento humano em regiões e segmentos mais vulneráveis. Portanto, este estudo teve como objetivo descrever o perfil e o desenvolvimento neuropsicomotor de crianças em condições de pobreza, divididas em dois grupos distintos: as beneficiárias do Programa Bolsa Família e as que não recebem tal benefício.

\section{Método}

\section{Participantes:}

Pelos propósitos do presente estudo, foram adotados como critérios de inclusão crianças de ambos os sexos, com idade entre 36 a 48 meses, que frequentassem as Unidades de Educação Infantil (antigas creches e pré-escolas) vinculadas à Secretaria Municipal de Educação, Prefeitura de Belém, localizadas nos oito distritos administrativos do município. Foram excluídas crianças que apresentassem distúrbios que afetam sua expressão da fala, alterações sensoriais, auditivas e/ou visuais e sequelas de comprometimento do sistema nervoso central (paralisia cerebral ou síndromes genéticas, por exemplo), além da apresentação de malformações, patologias osteoarticulares diagnosticadas ou qualquer outro tipo de patologias crônicas graves ou crônicas debilitantes.

Para o cálculo da amostra, foi utilizado o processo de amostragem por conglomerado. A margem de erro do cálculo amostral ficou em 5\% e o nível de confiança representa $95 \%$. Nesse sentido, como a população do estudo era composta por 1201 crianças, o tamanho de amostra ideal foi estabelecido em 300 delas. Todavia, adicionou-se um percentual de $7 \%$ na definição da amostra prevendo eventuais perdas ao longo da coleta de dados, o que totalizou 320 crianças. A amostra final após a coleta de dados foi de 319 crianças.

\section{Ambiente:}

Treze unidades de educação infantil dos oito distritos administrativos de Belém.

\section{Instrumentos e técnicas:}

Foram utilizados três instrumentos: o Questionário de Características Biopsicossociais da Criança (QCBC), o Teste de Triagem do Desenvolvimento Denver II (TTDDII) e o instrumento de medição do Nível de Pobreza Urbana (NPU).

O Questionário de Características Biopsicossociais da Criança (QCBC) foi elaborado pelas autoras para este estudo e contém um conjunto de itens, representando variáveis a serem analisadas ao longo da pesquisa e que foram selecionadas com base na literatura sobre fatores determinantes do desenvolvimento infantil. $O$ questionário é composto de 48 perguntas, sendo 19 abertas e 29 fechadas, além de um quadro especial para facilitar a computação do desempenho das crianças no Teste de Triagem do Desenvolvimento Denver II. O instrumento está estruturado em torno das seguintes categorias: identificação das crianças e pais (19 perguntas), história pré, peri e pós-natal (6 perguntas), condições socioeconômicas e ambientais (20 perguntas), ambiente de brincadeiras ( 3 perguntas) e quadro para coleta de respostas do Denver II.

O Teste de Triagem do Desenvolvimento Denver II, traduzido e adaptado por Pedromônico, Bragatto e Strobilius (1999), é um instrumento que permite avaliar o desempenho neuropsicomotor e identificar crianças com risco para atraso no desenvolvimento. O instrumento possui fidedignidade alta, sendo recomendado para uso em crianças entre zero a seis anos de idade. De maneira geral, o Denver II consiste em 125 itens, organizados em quatro dimensões: a) pessoal/social - aspectos da socialização da criança dentro/fora do ambiente familiar; b) motricidade fina/ adaptativa - coordenação olho/ mão, manipulação de pequenos objetos; c) linguagem - produção de som, capacidade de reconhecer, entender e usar a linguagem; e d) motricidade grosseira - controle motor corporal, sentar, caminhar, pular e todos os demais movimentos realizados através da musculatura ampla. Pelo TTDD II, os desfechos seriam três: atraso, risco ou normal. Porém, neste estudo, foi considerado o grupo com suspeita de atraso no desenvolvimento (incluem as crianças com risco e atraso), para a realização da análise estatística inferencial e em vista da larga utilização desta classificação na literatura brasileira. (Beteli, 2006; Halpern, Giugliani, Victora, Barros \& Horta, 2002).

E o instrumento Nível de Pobreza Urbana (NPU): Instrumento de medição do nível de pobreza proposto 
pelos pesquisadores chilenos Alvarez, Wurgaft e Salazar (1982), que foi traduzido e adaptado no Brasil por Issler e Giugliani (1997), voltado especialmente para populações urbanas de baixo nível socioeconômico. $\mathrm{O}$ instrumento compreende 13 itens referentes à constituição da família, escolaridade dos cuidadores, condições do domić́lio e peridomicílio e posse de alguns bens. A pontuação de cada item varia em uma escala de zero a quatro, sendo que a pontuação máxima obtida é de 52 e a mínima não menos que sete. A soma obtida em cada um desses itens estabelece o nível de pobreza urbana da família. Para fins de análise estatística, é recomendada a divisão em quartis da população de estudo, conforme a pontuação obtida na classificação do seu nível de pobreza. Cada quartil, como medida estatística utilizada para verificar a tendência central dos números, equivalente a $25 \%$ da distribuição dos dados. Em virtude da disposição das pontuações obtidas entre o presente estudo e o estudo de Issler e Giugliani (1997) foi necessário adotar outros pontos de corte para a estratificação da população quanto aos níveis de pobreza, já que a pontuação obtida na pesquisa variou de 28 a 52 pontos. Desse modo, famílias pertencentes ao quartil mais pobre da população (no caso, as $25 \%$ que obtiveram as menores pontuações até o limite de 41 pontos) foram consideradas como vivendo em "miséria", o que representou a faixa inferior na classificação dos níveis de pobreza. A população que apresentou pontuação de 42 a 47 foram encaixadas na categoria "baixa inferior", e as famílias que apresentaram as pontuações maiores, que variaram de 48 a 52 pontos foram encaixadas na categoria "baixa superior".

\section{Procedimento da Coleta de Dados:}

Foi solicitada autorização à Secretaria Municipal de Educação de Belém (SEMEC), mediante ofício, para realização da pesquisa nas UEI. Após a aprovação, a proposta de pesquisa foi submetida e aprovada pelo Comitê de Ética em Pesquisa com Seres Humanos do Núcleo de Medicina Tropical da Universidade Federal do Pará e foi aprovado, sob o número CAAE 05177512.5.0000.5172.

Posteriormente, realizou-se estudo piloto em uma escola pública em Belém-PA, com cinco crianças para treinamento dos pesquisadores quanto à aplicação do TTDDII, realizado apenas por profissionais e estudantes de fisioterapia e terapia ocupacional, e cálculo do tempo de aplicação desse instrumento. Em seguida, foi iniciada a coleta de dados nas 13 unidades de educação infantil, sendo destinada uma semana para realização da coleta em cada UEI. No primeiro dia de coleta era realizada a entrevista com o responsável pela criança e nos demais dias aplicado o TTDDII com as crianças nos dois turnos, manhã e tarde, preferencialmente no intervalo das atividades das crianças. O procedimento do trabalho respeitou o constante na declaração de Helsink bem como às Resoluções do Conselho Nacional de Saúde n. 196, de 10/10/96 e n. 251, de 07/08/97.

\section{Procedimento de Análise dos dados:}

As informações foram digitadas sobre uma estrutura previamente programada, no programa Microsoft Excel 2010. A seguir, esses dados foram transportados para o programa Statistical Package for the Social Sciences (SPSS) versão 20, onde foram analisados.

Inicialmente, foi realizada uma análise da distribuição das frequências das diversas variáveis. Depois, foi realizado um estudo comparativo entre as variáveis e a condição de suspeita de atraso no desenvolvimento, sendo utilizado o teste do qui-quadrado para esta análise. Em todas as análises foram considerados significantes os valores em que $p<0,05$.

\section{Resultados}

Esta seção está dividida de acordo com os três instrumentos utilizados na pesquisa, na seguinte ordem: Questionário das Características Biopsicossociais da Criança (QCBC), Teste de Triagem do Desenvolvimento Denver II (TTTDDII) e Instrumento de Medição do Nível de Pobreza Urbana (NPU).

\section{Questionário das Características Biopsicossociais da Criança}

Do total de 319 crianças que participaram da pesquisa $208(65,20 \%)$ são oriundas de famílias que apresentam renda mensal de um a três salários mínimos. A maior parte dos casos $252(78,99 \%)$, os pais eram responsáveis pela manutenção dos gastos com alimentação, transporte, moradia, e outros itens do orçamento doméstico. Em relação à presença de rendas complementares nas famílias, apenas uma contava com auxílio financeiro referente ao Benefício de Prestação Continuada (BPC) e 183 (57,36\%) das famílias estavam inscritas no Programa Bolsa Família. 
Tabela 1. Condições socioeconômicas e demográficas da população estudada.

\begin{tabular}{|c|c|c|}
\hline Variável & Total (N) & Total (\%) \\
\hline $\begin{array}{l}\text { Renda Familiar em salários mínimos } \\
<\text { de } 1 \text { salário } \\
1 \text { a } 3 \text { salários } \\
>\text { de } 3 \text { salários }\end{array}$ & $\begin{array}{c}98 \\
208 \\
13\end{array}$ & $\begin{array}{c}30,72 \\
65,20 \\
4,08\end{array}$ \\
\hline $\begin{array}{l}\text { Responsável pela renda } \\
\text { Pais } \\
\text { Pais e outros } \\
\text { Outros }\end{array}$ & $\begin{array}{c}252 \\
37 \\
30\end{array}$ & $\begin{array}{c}78,99 \\
11,59 \\
9,4\end{array}$ \\
\hline $\begin{array}{l}\text { Bolsa família } \\
\text { Sim } \\
\text { Não }\end{array}$ & $\begin{array}{l}183 \\
136\end{array}$ & $\begin{array}{l}57,36 \\
42,64\end{array}$ \\
\hline $\begin{array}{l}\text { Relação com o domicílio } \\
\text { Própria } \\
\text { Alugada } \\
\text { Outros (ocupação/morando de favor) }\end{array}$ & $\begin{array}{l}158 \\
75 \\
86\end{array}$ & $\begin{array}{l}49,54 \\
23,51 \\
26,95\end{array}$ \\
\hline $\begin{array}{l}\text { Idade materna } \\
<19 \text { anos } \\
20 \text { a } 29 \text { anos } \\
>30 \text { anos } \\
\text { Sem informação }\end{array}$ & $\begin{array}{c}10 \\
200 \\
104 \\
5\end{array}$ & $\begin{array}{c}3,14 \\
62,69 \\
32,60 \\
1,57\end{array}$ \\
\hline $\begin{array}{l}\text { Idade paterna } \\
<19 \text { anos } \\
20 \text { a } 29 \text { anos } \\
>30 \text { anos } \\
\text { Sem informação }\end{array}$ & $\begin{array}{c}1 \\
113 \\
152 \\
53\end{array}$ & $\begin{array}{l}0,31 \\
35,42 \\
47,64 \\
16,62\end{array}$ \\
\hline $\begin{array}{l}\text { Escolaridade materna } \\
0 \text { a } 8 \text { anos de estudo } \\
9 \text { a } 11 \text { anos de estudo } \\
12 \text { anos ou mais } \\
\text { Sem informação }\end{array}$ & $\begin{array}{c}76 \\
112 \\
129 \\
2\end{array}$ & $\begin{array}{c}23,82 \\
35,10 \\
40,43 \\
0,63\end{array}$ \\
\hline $\begin{array}{l}\text { Escolaridade paterna } \\
0 \text { a } 8 \text { anos de estudo } \\
9 \text { a } 11 \text { anos de estudo } \\
12 \text { anos ou mais } \\
\text { Sem informação }\end{array}$ & $\begin{array}{l}83 \\
95 \\
93 \\
48\end{array}$ & $\begin{array}{l}26,01 \\
29,78 \\
29,15 \\
15,05\end{array}$ \\
\hline $\begin{array}{l}\text { Ocupação materna } \\
\text { Trabalho informal } \\
\text { Trabalho regular } \\
\text { Não trabalha }\end{array}$ & $\begin{array}{c}104 \\
119 \\
94\end{array}$ & $\begin{array}{l}32,6 \\
37,30 \\
29,46\end{array}$ \\
\hline $\begin{array}{l}\text { Ocupação paterna } \\
\text { Trabalho informal } \\
\text { Trabalho regular } \\
\text { Não trabalha } \\
\text { Sem informação }\end{array}$ & $\begin{array}{l}164 \\
86 \\
20 \\
49\end{array}$ & $\begin{array}{c}51,41 \\
26,96 \\
6,26 \\
15,36\end{array}$ \\
\hline $\begin{array}{l}\text { Relação entre os pais } \\
\text { Casados } \\
\text { Separados } \\
\text { Solteira(o) ou viúvo (a) }\end{array}$ & $\begin{array}{l}182 \\
69 \\
68\end{array}$ & $\begin{array}{l}57,05 \\
21,63 \\
21,31\end{array}$ \\
\hline $\begin{array}{l}\text { Número de irmãos } \\
\text { nenhum } \\
1 \text { a } 2 \text { irmãos } \\
\geq 3 \text { irmãos }\end{array}$ & $\begin{array}{c}63 \\
196 \\
49\end{array}$ & $\begin{array}{l}19,74 \\
61,44 \\
15,36\end{array}$ \\
\hline $\begin{array}{l}\text { Principais cuidadores da criança } \\
\text { Pais } \\
\text { Pais e outros } \\
\text { Outros }\end{array}$ & $\begin{array}{c}251 \\
15 \\
53\end{array}$ & $\begin{array}{l}78,68 \\
4,7 \\
16,61\end{array}$ \\
\hline
\end{tabular}

Fonte: Banco de Dados do Laboratório de Ecologia do Desenvolvimento-UFPA. 
Observou-se que $98(30,72 \%)$ crianças viviam em famílias com renda menor que um salário mínimo. Entre as mães das crianças que participaram do estudo 119 $(37,30 \%)$ possuíam trabalho regular e $94(29,46 \%)$ não estavam trabalhando à época da pesquisa. No que diz respeito aos pais $164(51,41 \%)$ trabalhavam de forma irregular e $20(6,26 \%)$ não exerciam qualquer atividade assalariada ou que garantisse ganhos regulares.

Embora a maioria das famílias pertencesse à classe econômica baixa, a maior parte das mães 129 (40,43\%) possuía 12 anos de estudo ou mais, $76(23,8 \%)$ com menos de oito anos duas mães eram analfabetas). Quanto à idade $200(62 \%)$ mães estavam dentro da faixa etária de 20 a 29 anos e 10 (3,14\%) eram adolescentes (< 19 anos). Com relação aos pais 95 (29\%) possuíam 12 anos de estudo ou mais, tendo sido identificados quatro pais analfabetos. No que se refere à idade, a maioria apresentou 30 anos ou mais 152 (47,64\%).

Quanto à composição familiar observou-se que 182 (57\%) dos responsáveis referiram viver com companheiro (casados) e 68 (21,31\%) não apresentavam essa condição civil (solteiros ou viúvos) e quatro entrevistados do sexo masculino se denominaram "pais solteiros". Em sua maioria, os principais cuidadores das crianças eram os próprios pais $251(78,68 \%)$ e a maior parte delas 196 $(61,44 \%)$ possuía de um a dois irmãos.

Os resultados referentes à condição de moradia das famílias das crianças mostraram a sua exposição a determinados fatores ambientais, que são: 104 (32,60\%) famílias viviam em casas de madeira, $46(14,42 \%)$ não possuíam banheiro dentro dos domićlíos, $33(10,34)$ não possuíam agua encanada em casa, $62(19,43 \%)$ tinham acesso clandestino a rede elétrica, $108(33,85)$ viviam em casas de 1 a 2 cômodos e 80 (25,08\%) famílias viviam com mais de seis pessoas em um mesmo domicilio. O estudo de Alves (2012), apontou que dentre os fatores que influenciam no desenvolvimento humano, especialmente nos anos iniciais, a variável moradia é uma das mais significativas.

Tabela 2 Condições de Moradia e Exposição a fatores ambientais.

\begin{tabular}{|c|c|c|}
\hline Variável & Total (N) & Total (\%) \\
\hline $\begin{array}{l}\text { Tipo de Moradia } \\
\text { Alvenaria } \\
\text { Madeira } \\
\text { Alvenaria e madeira } \\
\text { Barro }\end{array}$ & $\begin{array}{c}190 \\
104 \\
23 \\
2\end{array}$ & $\begin{array}{l}59,56 \\
32,60 \\
7,21 \\
0,63\end{array}$ \\
\hline $\begin{array}{l}\text { Fornecimento de água } \\
\text { Encanada em casa } \\
\text { Encanada no terreno } \\
\text { Poço/ carregada do vizinho }\end{array}$ & $\begin{array}{l}276 \\
10 \\
33\end{array}$ & $\begin{array}{l}86,62 \\
3,13 \\
10,34\end{array}$ \\
\hline $\begin{array}{l}\text { Banheiro } \\
\text { Próprio interno } \\
\text { Próprio externo } \\
\text { Comunitário }\end{array}$ & $\begin{array}{l}255 \\
46 \\
18\end{array}$ & $\begin{array}{l}79,94 \\
14,42 \\
5,64\end{array}$ \\
\hline $\begin{array}{l}\text { Energia Elétrica } \\
\text { Ligação regular } \\
\text { Ligação Clandestina } \\
\text { Não possui }\end{array}$ & $\begin{array}{c}256 \\
62 \\
1\end{array}$ & $\begin{array}{l}80,25 \\
19,43 \\
0,31\end{array}$ \\
\hline $\begin{array}{l}\text { Coleta de Lixo } \\
\text { Coleta regular } \\
\text { Sem coleta }\end{array}$ & $\begin{array}{c}311 \\
8\end{array}$ & $\begin{array}{l}97,5 \\
2,82\end{array}$ \\
\hline $\begin{array}{l}\text { Número de cômodos da casa } \\
1 \text { a } 2 \text { cômodos } \\
\geq 3 \text { cômodos }\end{array}$ & $\begin{array}{l}108 \\
210\end{array}$ & $\begin{array}{l}33,85 \\
65,83\end{array}$ \\
\hline $\begin{array}{l}\text { Número de residentes na casa } \\
2 \text { a } 5 \text { moradores } \\
\geq 6 \text { moradores }\end{array}$ & $\begin{array}{c}239 \\
80\end{array}$ & $\begin{array}{l}74,92 \\
25,08\end{array}$ \\
\hline
\end{tabular}

Fonte: Banco de Dados do Laboratório de Ecologia do Desenvolvimento-UFPA 
$\mathrm{Na}$ amostra estudada, observou-se que $210(65,83 \%)$ das famílias residiam em casas com três ou mais cômodos, habitada por dois a cinco moradores 239 (74,92\%), o que coincide com os dados divulgados pelo IBGE, no Censo de 2010 (referência). O crescente número de domicílios, descritos pelo IBGE, ocorreu concomitante ao aumento do número de cômodos por domicílio. Os domićlios com cinco cômodos ou mais representavam 48\%, em 1960 e $70 \%$ no ano de 2010 (IBGE, 2012). Portanto, pode-se concluir que os dados desta pesquisa acompanham tendência sociodemográfica observada nos domicílios brasileiros: o aumento na disponibilidade de cômodos e a redução do número de moradores por unidade.

Um dado que chama a atenção neste estudo é que existe um percentual expressivo de pessoas 104 (32,60\%) que residem em domicílios de madeira ou mistos. Os dados diferem dos apresentados pelo IBGE (2012) a respeito dos domicílios no último Censo (data). Pois, segundo o instituto, do total de domicílios de Belém (81,54\%) são construídos de alvenaria, $18,16 \%$ de madeira e $0,30 \%$ de outros materiais.

\section{Teste de Triagem do Desenvolvimento Denver II - TTDD II}

Na população estudada $37,30 \%$ das crianças que participaram da triagem realizada em UEI do município de Belém foram incluídas na categoria que há indicação de atraso do desenvolvimento neuropsicomotor e $40,44 \%$ se encaixavam na categoria de risco e $22,26 \%$ delas apresentaram escore compatível com o status de normalidade. Contudo, como foi explicado anteriormente, neste estudo, para efeito de análise considerou-se somente duas amplas categorias de resultados: Desenvolvimento Normal (DN) e Desenvolvimento Suspeito (DS). Como se pode observar o estudo revelou que das 319 crianças triadas a partir do procedimento proposto248 (77,74\%) apresentaram desenvolvimento suspeito.

Tabela 3. Escore de desenvolvimento segundo TTDD II de crianças das UEI's de Belém - PA, 2013

\begin{tabular}{|c|c|c|}
\hline Escore & Quantidade & $\%$ \\
\hline Normal & 71 & 22,26 \\
\hline Suspeito & 248 & 77,74 \\
\hline Total & 319 & 100 \\
\hline
\end{tabular}

Fonte: Banco de Dados do Laboratório de Ecologia do Desenvolvimento-UFPA
A análise destes resultados globais obtidos pela aplicação do Teste de Triagem do Desenvolvimento Denver II mostrou que parte significativa da população de três anos das UEI pesquisadas apresentou resultado suspeito. Além disso, no presente estudo verificou-se que 183 (57,36\%) crianças recebiam o benefício do PBF e 136 (42,63\%) não eram beneficiárias do programa. Através do TTDDII, observou-se que do total de beneficiárias, 142 (77,60\%) apresentaram desenvolvimento considerado suspeito, sendo 77 meninas e 65 meninos. Apenas 41 (22,40\%) apresentaram desenvolvimento considerado normal, sendo 27 meninas e 14 meninos. Entre as crianças que não recebiam o benefício $106(77,94 \%)$ tiveram o desenvolvimento suspeito, 59 meninas e 47 meninos. O score considerado normal foi observado apenas em $30(22,05 \%)$ crianças não beneficiárias, 17 meninas e 13 meninos.

Percentualmente, observou-se que $242(77,74 \%)$ da amostra encontrava-se com o score de desenvolvimento suspeito ou com atraso e apenas $71(22,25 \%)$ do total de crianças apresentavam desenvolvimento considerado normal. Os dados mostraram que os perfis do desenvolvimento neuropsicomotor dos dois grupos prevalece o perfil que indica suspeita ou atraso no desenvolvimento e uma parcela pequena da amostra obteve score normal segundo o TTDDII. (Gráfico 1 na página seguinte).

\section{Nível de Pobreza Urbana (NPU)}

Em relação ao instrumento de medição do nível de pobreza das crianças pesquisadas, o escore mínimo obtido foi de 28 pontos e o máximo de 52 pontos, com 87 famílias classificadas dentro do nível de miséria $(27,27 \%)$ ( $45 \%$ sem benefício e $54 \%$ com benefício), 132 no nível baixo inferior (41,38\%) (47\% sem benefício e $52 \%$ com benefício) e 100 no nível baixo superior (31,35\%) (47\% sem benefício e $53 \%$ com benefício). A média total da amostra calculada ficou em 44 pontos e a moda de 45 pontos, com desvio padrão de 4,54 pontos. Estas medidas apontam certa homogeneidade na população estudada em termos do nível de pobreza apresentado pelas famílias.

Os dados deste instrumento foram correlacionados com o desempenho das crianças de acordo com o TTDD II e observou-se que as duas variáveis estão correlacionadas. Os resultados indicaram uma correlação significativa $(p=0,003)$ entre o índice do nível de pobreza e estado de desenvolvimento neuropsicomotor das crianças. Tais evidências tornam forte a hipótese de que condição de miséria apresentada por uma parte das famílias pode ter contribuído para aumentar as chances de a criança ter apresentado desenvolvimento classificado como suspeito. 


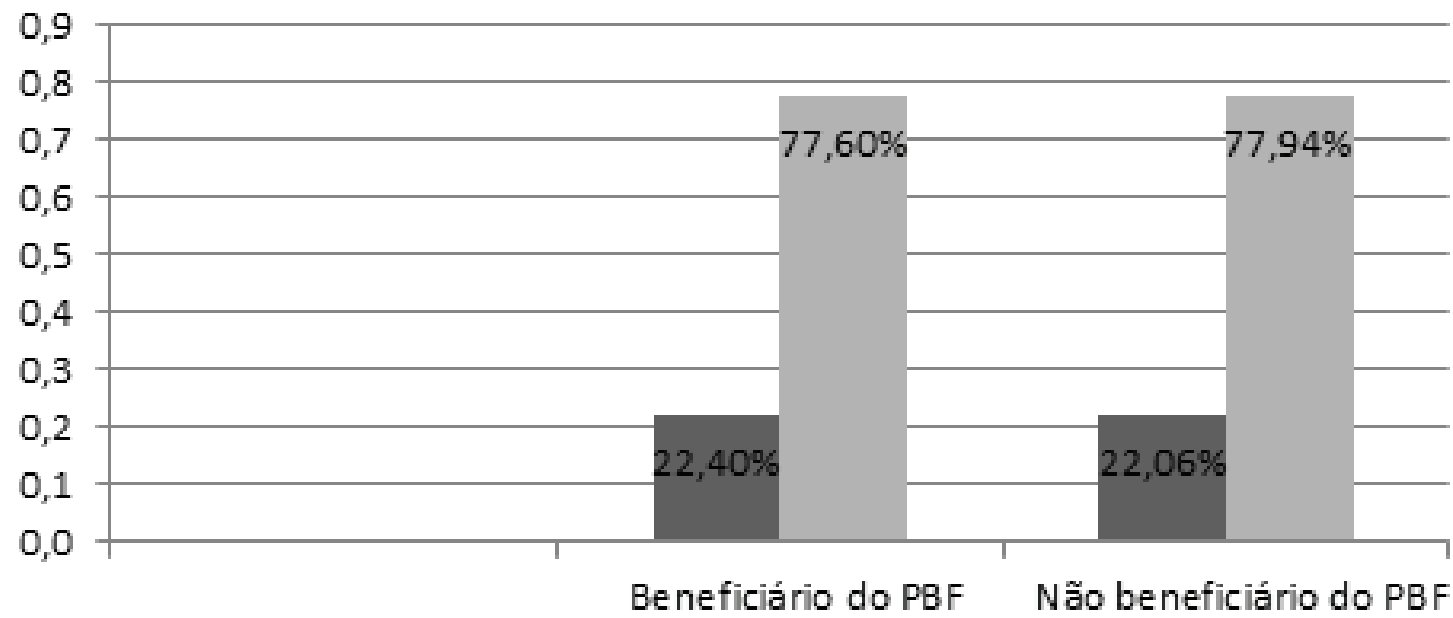

Normal (n)

Suspe ito $(n)$

Gráfico 1: Percentual do score do desenvolvimento

Fonte: Banco de dados do Laboratório de Ecologia do Desenvolvimento-UFPA

\section{Discussão}

Diante dos resultados apresentados é possível observar que alguns aspectos provavelmente explicam o perfil do desenvolvimento neuropsicomotor das crianças ser semelhante independente de complementação de renda através do PBF. Dentre eles destacam-se as variáveis ambientais, como renda familiar, condições de moradia, escolaridade dos pais e nível de pobreza urbano.

A variável renda familiar no presente estudo mostrou que a $98(30,72 \%)$ das crianças e suas famílias viviam com menos de um salário mínimo mensal. Apesar do consenso de que a pobreza não se limita ao aspecto econômico este é um fator que os estudos (referência) mostraram ser desfavorável ao desenvolvimento na infância na medida em que influencia diversos aspectos físicos, sociais e emocionais. Assim como, pode causar atrasos no desenvolvimento nas áreas de linguagem, cognitiva, motor entre outras por conta de fatores como subnutrição, privação social e desvantagem educacional. Além disso, afeta consideravelmente as relações familiares, o que contribui para o aumento da incidência de conflitos entre os pais e reflete diretamente no relacionamento destes com a criança (Moura Junior, Cidade, Ximenes \& Sarriera, 2014).

Um dado que chama a atenção neste estudo é que ainda existe um percentual expressivo de pessoas $(32,60 \%)$ que residem em domicílios de madeira ou mistos. Estes dados diferem dos apresentados pelo IBGE (2012) a respeito dos domicílios no último Censo, já que segundo o instituto, do total de domicílios de Belém $81,54 \%$ são construídos de alvenaria, 18,16\% de madeira e $0,30 \%$ de outros materiais. Este percentual significativo de casas de madeira pode justificar-se pelos achados de Sá et al. (2009) ao analisar a condição de superfície em que se encontram os domicílios precários do município de Belém. Este estudo demonstrou que as construções mais comuns localizadas em áreas consideradas alagáveis na cidade são de madeira, assim como o estudo realizado por Reis, Araújo, Santos, Silva e Pontes (2012), que pesquisou comunidades ribeirinhas, observou que prati-

Tabela 4. Associação entre o Nível de Pobreza Urbana das crianças que participaram do estudo $(\mathrm{N}=319)$ e os resultados do Teste de Triagem do Desenvolvimento Denver II, Belém-PA, 2013

\begin{tabular}{|l|c|c|c|c|}
\hline \multirow{2}{*}{ Nivel de Pobreza } & \multicolumn{2}{|c|}{ Escore Total } & \multirow{2}{*}{ Total } & \multirow{2}{*}{ P valor } \\
\cline { 2 - 3 } & Normal & Suspeito & & \\
\hline Miséria & 11 & 76 & 87 & $0,003^{*}$ \\
\hline Baixa inferior & 27 & 105 & 132 & \\
\hline Baixa Superior & 33 & 67 & 100 & \\
\hline Total & 71 & 248 & 319 & \\
\hline
\end{tabular}

Fonte: Banco de Dados do Laboratório de Ecologia do Desenvolvimento-UFPA 
camente na totalidade da amostra a presença de casas é em estilo palafitas (construídas de madeira), com apenas uma ocorrência de residência de alvenaria. O impacto dessas precárias condições de vida vai além da privação material e ambiental imposta aos moradores de regiões consideradas periféricas. Viver nesses locais, muitos sequer regularizados, deixa os moradores sem o usufruto de um amplo espectro de outros direitos humanos, civis e políticos, econômicos, sociais e culturais.

O estudo mostrou que aproximadamente $40 \%$ das mães das crianças tinham mais de 12 anos de estudo, já entre os pais apenas $29 \%$ tinha entre nove e 11 anos de estudo, o que corresponde ao ensino médio. A literatura (Cruz, Cavalcante \& Pedroso, 2014; Kobarg \& Vieira, 2008; Moura, Ribas, Piccinini, Bastos, Magalhães, Vieira, Salomão, Silva \& Silva, 2004) considera a baixa escolaridade dos pais, como um dos fatores que podem influenciar no desenvolvimento infantil, no que se refere à qualidade de estimulação ambiental oferecida as crianças e adolescentes, o que interfere no desenvolvimento adequado da linguagem e do vocabulário. Embora o desenvolvimento da linguagem seja algo previsível ao longo do tempo, são necessárias estimulações ambientais mínimas e, por consequência, pais com baixa escolaridade tendem a ter menos acesso a informações e considerar a importância de tais estímulos à criança (Delvan, Becker \& Braun., 2010; Sapienza \& Pedrômonico, 2005).

Em relação ao Índice do Nível de Pobreza das famílias, os dados deste instrumento foram correlacionados com o desempenho das crianças de acordo com o TTDD II e observou-se que as duas variáveis estão correlacionadas. Os resultados indicaram uma correlação significativa $(p=0,003)$ entre o índice de medição do nível de pobreza e o estado de desenvolvimento neuropsicomotor das crianças. Estas evidências podem ter contribuído para o percentual elevado de crianças apresentando o desenvolvimento classificado como suspeito. Isso porque, estudos nas áreas humanas e sociais têm demonstrado os efeitos nefastos que a pobreza ocasiona ao desenvolvimento humano, especialmente, ao infantil (Silva, 2013; Guimarães, Carvalho, Machado, Baptista \& Lemos, 2013; Lima \& Lima, 2012). Estes estudos demonstraram que viver na pobreza expõe as pessoas a situações consideradas de risco ao desenvolvimento, dentre eles: habitações pequenas, número considerável de pessoas dividindo o espaço, bairros considerados violentos, baixa escolaridade dos adultos e também o aparecimento de doenças. Viver na pobreza consiste em uma ameaça ao bem-estar do indivíduo e uma limita- ção colocada às oportunidades de desenvolvimento. As condições de pobreza em que as famílias se encontram não afetam apenas materialmente, mas, influenciam significativamente nas relações que estabelecem com seus cônjuges e filhos, bem como a exposição a desvantagens sociais e emocionais severas (Cachapuz \& Halpern , 2006; Pilz \& Scherman, 2007).

Além disso, crianças com atraso no desenvolvimento neuropsicomotor podem não desenvolver plenamente seu potencial pessoal e social ou ter dificuldades de exercer integralmente sua cidadania. O atraso no desenvolvimento para o desempenho de atividades esperadas para a faixa etária pode gerar desvantagens, tais como: abandono escolar, dificuldades de inserção no mercado de trabalho, entre outras (Delvan, Becker \& Braun, 2010; Evans \& Kim, 2013). Por isso, os primeiros anos de vida têm significativa importância para o desenvolvimento infantil, em decorrência do rápido crescimento cerebral e também o avanço cognitivo e motor. Sendo assim estes primeiros ciclos de vida estão vulneráveis as influências do contexto. O desenvolvimento infantil sofre influencias desde a sua concepção, $\mathrm{t}$ tanto de fatores biológicos durante o período de pré/pós-natal quanto a interação destes aspectos com fatores socioeconômicos do ambiente familiar, que estão intimamente ligados ao desenvolvimento saudável ou não da criança. Desta forma, o ambiente familiar tanto pode permitir quanto coibir o potencial de desenvolvimento da criança (Evans \& Kim, 2013).

\section{Considerações finais}

No percurso deste artigo, buscou-se descrever o perfil e o desenvolvimento neuropsicomotor de 319 crianças beneficiárias e não beneficiárias do Programa Bolsa Família, que frequentavam unidades de educação infantil no município de Belém. A pesquisa contribuiu no sentido de descrever o perfil do desenvolvimento neuropsicomotor de dois grupos de crianças, beneficiárias e não beneficiárias do PBF. Demonstrou que, independentemente, de renda complementar as crianças e suas famílias dos dois grupos encontra-se em situações socioeconômicas muito semelhantes: bairros periféricos, domicílios pequenos e muitas vezes, sem acesso a serviços básicos fundamentais na primeira infância, como saúde e educação.

Quando as famílias conseguem acessar esses serviços, geralmente os que são oferecidos podem não apresentar uma qualidade adequada. Além disso, entende-se que a renda familiar insuficiente e a má qualidade dos serviços acessados por famílias pobres no Brasil ainda não favorecem o prenúncio de mudanças efetivas na 
condição de vulnerabilidade econômica e social na qual vivem em diferentes regiões do país.

$\mathrm{O}$ estudo apontou que existe uma significativa correlação entre o Nível de Pobreza Urbana das famílias e o desenvolvimento neuropsicomotor suspeito das crianças. Estes dados apontam a influência direta que as condições socioeconomicas exercem sobre o desenvolvimento infantil e a importância de se pensar o alcance das políticas públicas sociais na vida de famílias em situaçção de pobreza. A pesquisa contribuiu de maneira significativa para o debate teórico e social acerca do tema, além de, apresentar um panorama relevante sobre a situação de crianças e suas respectivas famílias em situação de vulnerabilidade social no município. Entretanto, vale ressaltar a necessidade do desenvolvimento de novos estudos nesta linha de investigação, para melhor compreender a criança e o seu contexto. Sugere-se estudos que estudem a região metropolitana em sua totalidade, ou comparando contextos diferentes dos já pesquisados.

\section{Referências}

Ammann, S.B. (2013). Expressões da pobreza no Brasil: análise a partir das desigualdades regionais. São Paulo: Cortez.

Alvarez, M.L; Wurgaft, F. \& Salazar, M.E. (1982) Medicionesdel nível socioeconômico bajo urbano em famílias com lactante desnutrido. Archivos Latino americanos de Nutrición, 32, 650-662.

Alves, L.L. (2012) Condições ambientais, familiares e sociais de crianças atendidas no centro de atenção psicossocial infantil de uma capital do centro-oeste. Dissertação de Mestrado. Puc-Goiás

Behring. E. (2003). Brasil em contra-reforma-desestruturação do Estado e perda de direitos. SP: Cortez.

Beteli, V.C. (2006) Acompanbamento do desenvolvimento infantil em creches. Escola de Enfermagem da Universidade de São Paulo. São Paulo, SP.

Brasil. (2015). Ministério do Desenvolvimento Social e Combate à Fome. Beneficios.

Cachapuz, R. F; Halpern, R. (2006). A influência das variáveis ambientais no desenvolvimento da linguagem em uma amostra de crianças. Revista da AMRIGS, 50(4), 292-301.

Cidade, E. C., Moura Junior, J. F., \& Ximenes, V. M. (2012). Implicações psicológicas da pobreza na vida do povo latino-americano. Psicologia argumento, 7(4), 87-98.

Cole, M., \& Cole, S. (2008). O desenvolvimento da criança e do adolescente. Porto Alegre: Artmed.

Cruz, E. J. S., Cavalcante, L. I. C., \& Pedroso, J. S. (2014). Inventário do Conhecimento do Desenvolvimento Infantil: estudo com mães de crianças em acolhimento institucional. Revista da SPAGESP, 15(1).

Delvan, J. D. S., Becker, A. P. S., \& Braun, K. (2010). Fatores de Risco no Desenvolvimento de Crianças e a Resiliência: um estudo teórico. Revista de Psicologia da IMED, 2(1), 349-357.

Eickmann, S. H., Malkes, N. F. A., \& Lima, M. C. (2012). Desenvolvimento neuropsicomotor de lactentes pré-termo com 6 a 12 meses de vida. Med J, 130, 299-306. doi: 10.1590/S1516-31802012000500006

Engel de Abreu, P. M. J., Tourinho, C. J., Puglisi, M. L., Nikaedo, C., Abreu, N., Miranda, M. C., Befi-Lopes, D. M.,

Bueno, O. F. A., \& Martin, R. (2015). A Pobreza e a Mente: Perspectiva da Ciência Cognitiva. Walferdange, Luxembourg: The UniversityofLuxembourg.

Evans, G. W., \& Kim, P. (2013). Childhood poverty, chronic stress, selfregulation, and coping. Child Development Perspectives, 7(1), 43-48. doi: $10.1111 /$ cdep. 12013
Guimarães, A. F., de Carvalho, D. V., Machado, N. Á. A., Baptista, R. A. N., \& Lemos, S. M. A. (2013). Risco de atraso no desenvolvimento de crianças de dois a 24 meses e sua associação com a qualidade do estímulo familiar. Revista Paulista de Pediatria, 31(4), 452-458.

Halpern, R., Giugliani, E. R., Victora, C. G., Barros, F. C., \& Horta, B. L. (2002). Fatores de risco para suspeita de atraso no desenvolvimento neuropsicomotor aos 12 meses de vida. Revista chilena de pediatria, 73(5), 529-539.

Issler, R.M.S., \& Giugliani, E.R.J. (1997). Identificação de grupos mais vulneráveis à desnutrição infantil pela medição do nível de pobreza. Jornal de Pediatria, 73(2):101-105

Kobarg, A. P. R., \& Vieira, M. L. (2008). Mothers' beliefs and practices about child development in rural and urban contexts. Psicologia: Reflexão e Crítica, 21(3), 401-408.

Lima, A. K. P., \& Lima, A.O. (2012). Perfil do desenvolvimento neuropsicomotor e aspectos familiares de crianças institucionalizadas na cidade do Recife. Revista CES Psicologia, 5(1), 11-25.

Moura Júnior, J.F., Cidade, E.C., Ximenes, V.M., Sarriera, J.C. (2014). Concepções de pobreza: um convite à discussão psicossocial. Temas em Psicologia, 22 (2), 341-352.

Moura, M. L. S. D., Ribas Jr, R. D. C., Piccinini, C. A., Bastos, A. C. D. S. B., Magalhães, C. M. C., Vieira, M. L.,\& Silva, A. K. D. (2004). Conhecimento sobre desenvolvimento infantil em mães primíparas de diferentes centros urbanos do Brasil. Estudos de Psicologia (Natal), 9(3), 421-429.

Pedromônico, M. R. M., Bragatto, E. L., \& Strobilus, R. (1999). Teste de Triagem Denver II. São Paulo, SP: Unifesp.

Pilz, E. M. L., \& Schermann, L. B. (2007). Determinantes biológicos e ambientais no desenvolvimento neuropsicomotor em uma amostra de crianças de Canoas/RS. Ciência saúde coletiva, 12(1), 181-90. doi: 10.1590/ S1413-81232007000100021

Rizzini, I. (2009). População infantil e juvenil: direitos humanos, pobreza e desigualdades. Direitos bumanos e questão social na América Latina. Rio de Janeiro: Ed. Gramma.

Reis, D.C., Araújo, M.E.C., Santos, S.S.L., Silva, S.S.C., Pontes, F.A.R. (2012). Araraiana e Combu: um estudo comparativo de dois contextos ribeirinhos amazônicos. Temas em Psicologia, 20(2), 429-438.

Rosinke, J. G., Heck, C. R., Dalfovo, W. C. T., \& Ruscheinsky, A. (2016). Efeitos sociais e econômicos para o desenvolvimento local através das contribuições do Programa Bolsa Família no município de Sinop-MT no período de 2004 a 2009. Interações-Revista Internacional de Desenvolvimento Local, 12(1). doi: 10.1590/S1518-70122011000100008

Sá, M.E.R; Lopes, R.; Cruz, S.H.R; Costa, S.G; Cardoso, W. S. (2009). Questão da moradia e assentamentos precários em Belém/PA: caracterização e classificação. In: Encontro Nacional da ANPUR-XIII EN Anpur. Florianopolis. Anais do XIII Encontro Nacional da ANPUR. Florianopolis: Editora da Universidade Federal de Santa Catarina, v. 1. p. 211-211.

Sapienza, G., \& Pedromônico, M. R. M. (2005). Risco, proteção e resiliência no desenvolvimento da criança e do adolescente. Psicologia em estudo, 10(2), 209-216.doi: 10.1590/S1413-73722005000200007.

Moura, M. L.S., Ribas, R. C., Piccinini, C. A., Bastos, A. C. Magalhães, C. M. C., Vieira, M. L., Salomão, N. M. R., Silva, A. M. P. M., \& Silva, A. K. (2004). Conhecimento sobre desenvolvimento infantil em mães primíparas de diferentes centros urbanos do Brasil. Estudos de Psicologia, 9, 421-429.

Silva, A. C. (2013). Pobreza, desenvolvimento mental e desempenho escolar. Cadernos de Pesquisa, (29), 7-9.

Silva, M. O. D. S. (2007). O Bolsa Família: problematizando questões centrais na política de transferência de renda no Brasil.

Silva, M. O. D. S. (Ed.). (2013). O Bolsa Família no enfrentamento à pobreza no Maranhão e Piauí.

Silva, M.O.S., Yazbek, M.C., Giovanni, G.D. (2011). A Política Social Brasileira no Século XXI: A prevalência dos programas de transferência de renda. 5. ed. São Paulo: Cortez.

Soares, F. V., Ribas, R. P., \& Osório, R. G. (2010). Evaluating the impact of Brazil's BolsaFamilia: Cash transfer programs in comparative perspective. Latin American ResearchReview, 45(2), 173-190.

Submetido em: 11-2-2017

Aceito em: $31-7-2017$ 